\title{
LETTERS
}

\section{Proton beam therapy should remain in the public domain}

We would like to respond to the article "Proton beam therapy for cancer" by Tsang and Patel that was published recently in CMAJ. ${ }^{1}$

As the authors state, radiotherapy is a critical element of treatment for one-third to half of all patients with cancer. Over the past 2 decades, there have been substantial improvements in the way radiotherapy is delivered - one of the most important being proton beam therapy, which allows greater sparing of normal tissue adjacent to the tumour than other forms of radiotherapy. This is especially important for children and young adults, whose overall survival in Canada is currently greater than $80 \%{ }^{2}$ and who are particularly vulnerable to potentially devastating long-term effects of treatment.

Currently, no proton beam facility exists in Canada, and patients deemed eligible receive this therapy at proton centres in the United States at a cost often exceeding $\$ 250000$ per patient, paid for by provincial health plans. ${ }^{3}$ In Quebec, there is a well-established process for referral for treatment with proton therapy in the US, but the number of children and young adults who currently benefit from this treatment is lower than expected: for example, some are simply not well enough after major operations to travel.

As Tsang and Patel mention, a private corporation has recently expressed an interest in building a stand-alone proton therapy facility in Montreal. In our opinion, developing proton therapy as a stand-alone private initiative is wrong for several reasons.
Perhaps most importantly, receiving treatment at a private facility could introduce major risks for the patients. Most children younger than 5-7 years - a substantial proportion of all children with cancer who require radiotherapy - will need to undergo treatments under anesthesia. A serious complication occurring away from the support of a pediatric care facility could be devastating.

As well, since radiation therapy is part of a multidisciplinary cancer treatment strategy that, in pediatric practice, almost always combines surgery and chemotherapy and requires intensive supportive care, it is highly preferable that proton therapy be geographically embedded in a multidisciplinary environment that can provide this type of complete care. Such an environment also provides the university setting needed for cuttingedge research and technology development and professional training programs critical to this type of technology. In comparable economies, such as the Netherlands and France, all recent proton centres have been embedded in existing hospital settings.

Finally, a privately owned and operated facility lacks economic sense. Although each treatment would likely be 40\%-50\% cheaper than sending patients to the US, the proposal estimates a cost of more than $\$ 100000$ per patient. ${ }^{4} \mathrm{~A}$ public facility could decrease that cost to $\$ 20000$, saving some $\$ 10$ million per year for our provincial health system. ${ }^{5}$ Moreover, as the use of protons expands, the total cost to the provincial health plans of treating more patients in a private facility would only increase.
In a public health system, operating an expensive and cutting-edge facility in the private sector goes against all convention. It makes no sense financially, logistically or academically and is potentially dangerous for the patients who stand to benefit most. Proton therapy should remain in the public domain.

\section{Tarek Hijal MD CM MSc}

Director, Division of Radiation Oncology, McGill University Health Centre, Montréal, Que.

\section{Carolyn R. Freeman MBBS}

Radiation oncologist, McGill University Health Centre, Montréal, Que.

\section{Jan Seuntjens PhD}

Director, Medical Physics Unit, McGill

University, Montréal, Que.

Cite as: CMAJ 2019 November 18;191: E1284. doi: 10.1503/cmaj.73445

\section{References}

1. Tsang DS, Patel S. Proton beam therapy for cancer. CMAJ 2019;191:E664-6.

2. Canadian Cancer Society. What is the probability of surviving cancer in Canada? Net survival by sex, age, geography and year. In: Canadian cancer statistics 2019. Ottawa: Canadian Cancer Society; 2019:62.

3. Mombo NN, Framarin A, Boulanger J, et al. Mise à jour des indications de la protonthérapie en oncologie. Québec: INESSS; 2017:43.

4. Perreault M. Protonthérapie: Québec a choisi le privé, déplorent des médecins. La Presse 2018 Sept. 4. Available: www.lapresse.ca/actualites/ sante/201809/04/01-5195107-protontherapie -quebec-a-choisi-le-prive-deplorent-des-medecins .php (accessed 2019 Aug. 15).

5. Forero DF, Dendukuri N. Offering proton beam therapy for selected types of cancer in children and adults at the MUHC: a budget impact analysis. Montreal: Technology Assessment Unit of the McGill University Health Centre; 2019.

Competing interests: None declared. 